accommodation, unless they were shut against persons labouring under other severe diseases-a measure which, at the approach of winter especially, would add much to the distress of the poor.

6 th. In conclusion, the committee would urge on the rich, who have comparatively little to fear for themselves, the great duty of generously and actively ministering to the relief of the poor, while the epidemic prevails; bearing in mind that fuel, and warm clothing, and sufficient nourishment, are powerful safeguards against the disease.

They deem it most desirable that the parish authorities should at once improve the diet, and increase the comforts, of the poor under their charge; and that the wealthy should form sacieties for the supply of food, clothing, and fuel, to those who, though not paupers, still need charitable assistance in the present emergency.

Such measures, which it is the duty of those possessed of power and wealth to adopt, would, the committee believe, if liberally carried out, deprive the cholera of half its victims.

College of Physicians, Oct. 28, 1848.

John Atrton Paris, President. Francis Hawkins, Registrar.

FEVER HOSPITALS IN IRELAND.

(Abstract of a Manifesto of the Central Board of Health, Dublin, 11th October, 1848.)

THE Board of Health set out by asserting that they " have had under consideration those provisions of the amended Fover Act, 12 Vic. c. 131, which have reference to the salaries of the medical officers at the temporary fever hospitals, and are of opinion, that five skillings a day, hitherto allowed to medical practitioners for attendance on temporary fever hospitals or dispensaries within their own districts, is only a reasonable remuneration for the labour and risk incurred in such attendance, and that it should not be departed from. (!)

"Representations have been laid before the board of the expediency of constructing a scale which might apportion the rate of remuneration to the relative sizes of the temporary fever hospitals, and the corresponding amount of duty to be performed. The board, after full consideration, are convinced that it would be hardly practicable to establish any such scale. The numbers under treatment in each hospital must necessarily vary from week to week, and if the numbers in hospital were permitted to be the criterion of the amount of salary, the medical officer would be constantly exposed to the imputation of retaining a greater number of patients than necessary, in order to entitle him to a certain amount of salary."

The board objects to providing for the attendance of the temporary fever hospital by the medical officer already holding the workhouse hospital, or other appointments under the board of guardians; and they add-

"If attendance on a temporary fever hospital be in itself worth a certain rate of remuneration, that amount of remuneration should be given for that particular duty, without reference to any other appointment which the officer may hold-each duty should be estimated for, and paid for in respect only to itself."

They also remark-

" Every practitioner requires a considerable portion of each day for private practice, which is generally the main source of his income; and if a greater amount of hospital duty be imposed on a medical officer than he can perform within from one to three hours at, the very farthest, the sick poor must be neglected.

"In England, the practice has grown up of medical officers undertaking a greater amount of medical attendance than they conld themselves adequately discharge, and of committing the care of the sick poor to assistants engaged for that purpose. The board most strongly disapprove of such a system: for it is evident that there can be no sufficient security for the professional knowledge or conduct of assistants so employed.

"Adequate skill and attention can only be afforded and secured to the poor by not imposing upon any medical officer any greater extent of public duty than he can honestly and fairly discharge, without trenching on his private practice."

\section{A PLAN FOR THE REGISTRATION OF CHOLERA CASES.}

To the Editor of THE LanceT.

Sir,-I forward for publication in ThE LANCET, the plan for oniformly reporting cases of cholera drawn up by the com-

mittee of the Western Medical and Surgical Society appointed to carry out the Society's resolutions of the 13 th instant. It is intended, that in the course of this, or early in next week, copies of this plan shall be in the hands of every practitioner in the district to which the Society intends to limit its operations. It is known that a great number-it is hoped and believed that all-to whom the forms are distributed, will take the trouble of filling them up with the details of any case which may occur, and of returning them to the Society. It will be the business of the committee hereafter to tabulate and analyze the returns thus obtained, and to make public the results.

Besides an accurate report of cases of cholera, it is felt by the committee to be highly necessary to obtain information as to the nature and peculiarities of the diseases now and for some time past prevalent in the district-information which may throw light on what is termed the "epidemic constitution" of the period, and especially to have some return of cases of severe diarrhœa and other disorders, always more or less pre. valent during an epidemic of cholera, and which may fairly be regarded as manifestations of the peculiar virus, short of its full effect-the perfect development of the disease. To arrive at this, and at information on various points respecting cholera itself, to which it is difficult to call attention in a table, a circular letter will be drawn up, and will follow as early as possible the distribution of the forms.

I trust that the plan now set on foot by our Society will be taken up by other societies and associations throughout the kingdom. No time is to be lost. Already, in England alone, nearly two hundred cases have occurred, of many-perhaps of most of which no record is preserved, and fresh cases are occurring every day.

I hope, Sir, to have your powerful aid in stirring up the profession to the requisite exertion. I have only to add, that to the secretary of any society or association who will apply to me, by letter or personally, I shall have great pleasure in giving every explanation in my power, both as to the manner of working the scheme, and as to the expense \&c. necessarily attending it. - I have the honour to be, Sir, your faithful servant,

Sloane-street, Oct. 31, 1848.

Enward C.Seaton, M.D. Hon. Sec. to the Western Medical and surgical society.

The tabular sheet forwarded to us by Dr. Seaton contains places for the number of the case, date, name and occupation, sex, age, habits, previous health, and residence of the patient, and the nature of the locality. Then for the history of the case up to the appearance of the first characteristic symptomsviz., the day and hour of seizure, supposed exciting cause of the attack, diet within the preceding twenty-four hours, medicine already taken, \&c. For the characteristic symptoms of the developed disease, eight columns are appropriated for observations severally on the conditions of the countenanee, tongue, skin, pulse, heart, voice, respiration, stools, cramps, thirst, urinary secretion, nervous system, \&c., and for the termination of the case. Ruled lines are also added for noting the condition of each separate organ at post-mortem examinations. Dr. Seaton has desired us to add, that he, or other members of the committee, will be happy to supply copies to legallyqualified practitioners who may make application for the same. We need hardly add, that every gentleman, if not applying personally, ought to forward a stamped envelope for the sheet; and it appears to us that it must weigh more than half an onnce, and that therefore two stamps will be requisite for it to pass postage free.

\section{TREATMENT OF ACUTE ULCERS BY LOCAL DEPLETION. \\ To the Editor of THE LANCET.}

Sir, - In the lecture of Mr. Critchett, published in Tyk LANCET of October 28, I find the following observations respecting an important point in the treatment of acute ulcers:- " In ulcers of an acute character, with considerable amount of surrouuding inflammation, some surgeons recommend local depletion applied to the circumference of the sore, either by means of leeches, or small lancet punctures. I must enter a strong protest against this plan of treatment. I do not deny that considerable temporary benefit and relief from pain may result from it, but, on the other hand, I have so frequently seen cases in which these artificial wounds, slight though they seem, have become troublesome sores, and in which no improvemen has been produced in the original ulcer, that I am convinced 